\title{
Use of closed loop system using Arduino for different parameters in farming
}

\author{
Saifur Rahman \\ Department of EE, Faculty of Engineering, Najran University, Saudi Arabia
}

\begin{tabular}{l}
\hline \hline Article Info \\
\hline Article history: \\
Received Aug 26, 2019 \\
Revised Oct 30, 2019 \\
Accepted Dec 11, 2019 \\
\hline
\end{tabular}

\section{Keywords:}

Andriod application

Arduino

Automated watering system

Farming

GDP (gross domestic product)

Hygrometer sensor

\begin{abstract}
The GDP (Gross domestic product) of most countries in the world are base on the regular basis of agriculture contribution of that particular country. The current weather conditions in the world and crop loss are the main reason for its contribution to GDP. New technologies and advanced fertilizers are now used in farming though these technologies and advanced fertilizers do not reach farmers till now. In this paper, a concept for the automated watering system in agriculture is introduce which uses wireless sensors technology for the detection of moisture in the soil suitable for agriculture using a smartphone application which will play a critical role in agriculture. The automatic watering to plants using the Arduino system and android app is use. Even this application of Android will provide information to the farmers related to agriculture like costs of seeds, level of moisture required, amount of water needed, which type of soil required, forecast weather, fertilizers to be used and pesticides required.
\end{abstract}

This is an open access article under the CC BY-SA license.

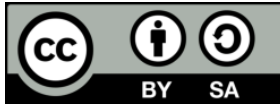

\section{Corresponding Author:}

Saifur Rahman,

Department of EE, Faculty of Engineering,

Najran University,

King Abdul Aziz Road, Najran-1988, Saudi Arabia.

Email: srrahman@nu.edu.sa

\section{INTRODUCTION}

Many sectors related to agriculture are the pillars of the world's economy as they are the primary means of livelihood in rural parts of most of the countries in the world. The financial value of all the complete goods and services produced in the country in a precise period is referred to as GDP. Agriculture has been contributing mainly to GDP to many nations over the years. One can take the example of India, i.e., in 2012-2013 cultivation added to 13.9 percent of the total gross domestic product [1] and provided $47 \%$ of the entire human resources of the country [2]. If one takes the example of India, the efforts are made by the government of central and state and the people have been successful in accomplishing the production of 264 MT of edibles grain during the year 2013-2014 [3, 4].

It is observe that the contribution of agriculture to GDP is not straightforward, i.e., non-linear from the year 1951 to 2019. There are many reasons which are responsible for this decline like diversification and growth of the Indian economy, adverse weather conditions which lead to crop loss, Framer does not know new technologies which they can use for the betterment of overall profit from agriculture and its related sectors. Despite all these problems agriculture is a cardinal source of employment and plays a vital role in the socio-economic development of countries.

To improve the above conditions discussed, one can make use of new technologies in the agriculture field. In recent years, the use of the mobile phone has become a characteristic fashion in the whole world irrespective of the age group. The majority of the people use the smartphone which is having android as 
an operating system and is becoming popular because in this one can use the internet using $3 \mathrm{G}$ and $4 \mathrm{G}$ connectivity, wireless local area network connectivity, having hardware like GPS, accelerometers.

If one talks about India, the Ministry of Agriculture, Government of India, has taken various steps in the interest of farmers for their growth as well as countries growth. The Honorable President of India in the year 2013 July inaugurated mKisan portal which got around 1,85,40,07,285 messages, 5,74,40,63,746, and 237,777 pieces of advice till 8th of April 2015 [5]. The price of seeds and fertilizers are around Rs. 5/month/dealer and are available weekly/daily with dealers [5]. In India applications like Krishi Ville [6], Kissan Kerala [7-15] is an effort to deliver information regarding farming to the farmers through the internet. The number of people is surprised by the fast emergence of mobile technology and considers mobile devices connect this world. wireless sensor network (WSN) is also a developing technology that can be used at an accelerated pace in the present time. WSN syndicates sensing, computation and communication into a single tiny device. Managing the use of water by controlling irrigation in response to the change in soil moisture to meet crop water demands is a great approach but requires knowledge of closed-loop control practice. Monitoring mechanisms that ensure efficient crop growth are essential on many farms, especially in some regions of the planet where the level of water is deficient [16-20].

The current conditions of farmers are not very good in most of the countries. There is a various reason related to these conditions such as high cost of life, e.g., education, health, etc., poor management is also one of the ideas for their severe circumstances. In India, in the past 16 years, it is observed that around a quarter of a million Indian farmers have committed suicide. Thus it is essential to improve the living style of farmers with the help of new technologies implementation.

The mobile application which has been proposed would work as a farmer's assistant in the field. These mobile applications will provide important agriculture information like a forecast of weather, prices of crops, costs of fertilizer and seeds, about pesticides to be used, type of soil required for particular seeds and moisture level required. Therefore this mobile application will be handy for farmers as they will be able to seek information regarding agriculture with just a few clicks. More ever, the application will reduce the fieldwork of farmers by providing the control to water plants [21-25].

There are two problems faced by farmers are: 1) Farmers are not aware of various new technologies that are useful for productive farming. 2) As the weather conditions are disturbed in most countries and water resources are limited, there is an acute need for using water efficiently. To deal with this problem, a system is proposed, smart framing using Arduino. According to this system, there will be an information hub from which farmers will get information about the latest technology in the agriculture field, and farmers will be updated with new technologies in the field of agriculture. Apart from this, there will be an automated watering system that will reduce the burden of farmers, and also it will use the limited supply of water efficiently.

\section{ARCHITECTURE OF THE DEVELOPED SYSTEM}

In a Closed Loop system, the farmer can make a general control strategy for a watering system using Arduino. For instance, generalized methodology is made; the central unit will work by designing an accurate conclusion on when and how much the amount of water to be given. Sensors are needed to provide feedback for this kind of system as shown in Figure 1. Sensors data are used to make decisions during farming. Regularly reporting and supervision of networks are carried out. The data of different parameters used in agriculture are required like the level of ground moisture, temperature, the speed of the wind, etc., by the controller of the closed-loop. The components used to develop this system are mentioned below:

Arduino is a public domain model built on befitting hardware and software which can be changed according to the need of the customer [1]. With the help of a controller, Arduino UNO board of microcontroller ATmega328P helps control motors. The formulating of the Arduino board is organized in such a manner that it will detect the level of moisture in the soil and gives a message to the farmer [8]. The hygrometer sensor is used to identify the content of moisture levels in the ground. When the level of moisture content falls below a threshold level, then the soil hygrometer detection outputs a high standard and vice versa. When this sensor is integrated with Arduino based module the automatic watering plant system is formed in which no human supervision is needed for watering of crops. Ethernet Shield is used to connecting the Arduino with the internet easily. This enables the Arduino to send and receive data from anywhere in the world with an internet connection required which can be used for the real-time application. By motor using Arduino controller of the Arduino, the speed and direction of the engine are controlled and this also permits an extra motor to be added by using the outside supplication of power supply of up to $12 \mathrm{~V}$. When we integrate the servo motor with a sensor, it allows controlling the angular position. The mechanism involved in the servo motor removes the error in the system using negative feedback and hence improves the performance of the system. Android is an open-source operating system that 
is mostly used in smartphones nowadays. In most of the countries in the world, almost $70 \%$ of mobile phone users are using Android as it is user-friendly. Android apps are designed and developed using tools like Android Studio, Eclipse, Visual Studio, etc.

There are two primary functional units for its working, i.e., soil hygrometer sensor and servo motor (water pump). The work of the soil hygrometer sensor is to check the level of moisture in the soil and then send a signal to the Arduino UNO if watering is required or not. The hardware block diagram representation of the system is as shown in Figure 1. In this paper, the Arduino controller is used to control the motor. Arduino and Android applications will communicate with each other via the internet. The working of the plant watering system is shown in Figure 2 in the form of a flowchart.

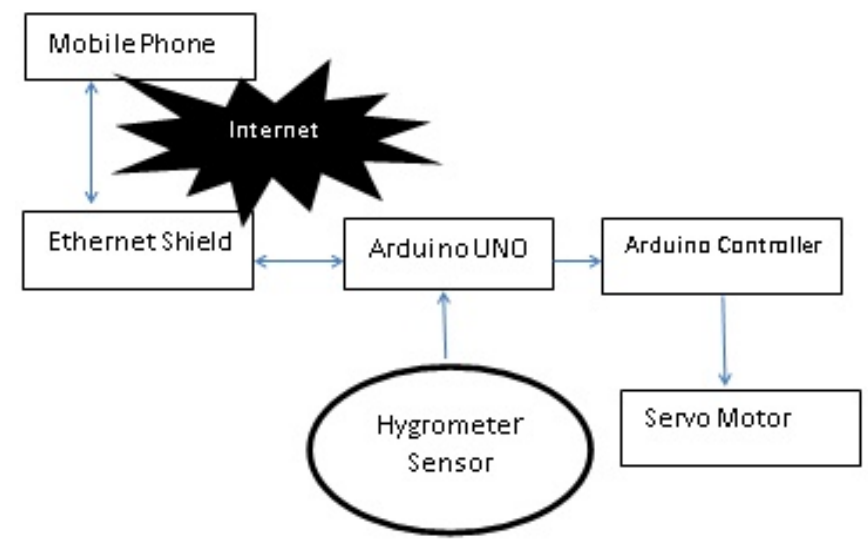

Figure 1. Block diagram of the hardware representation

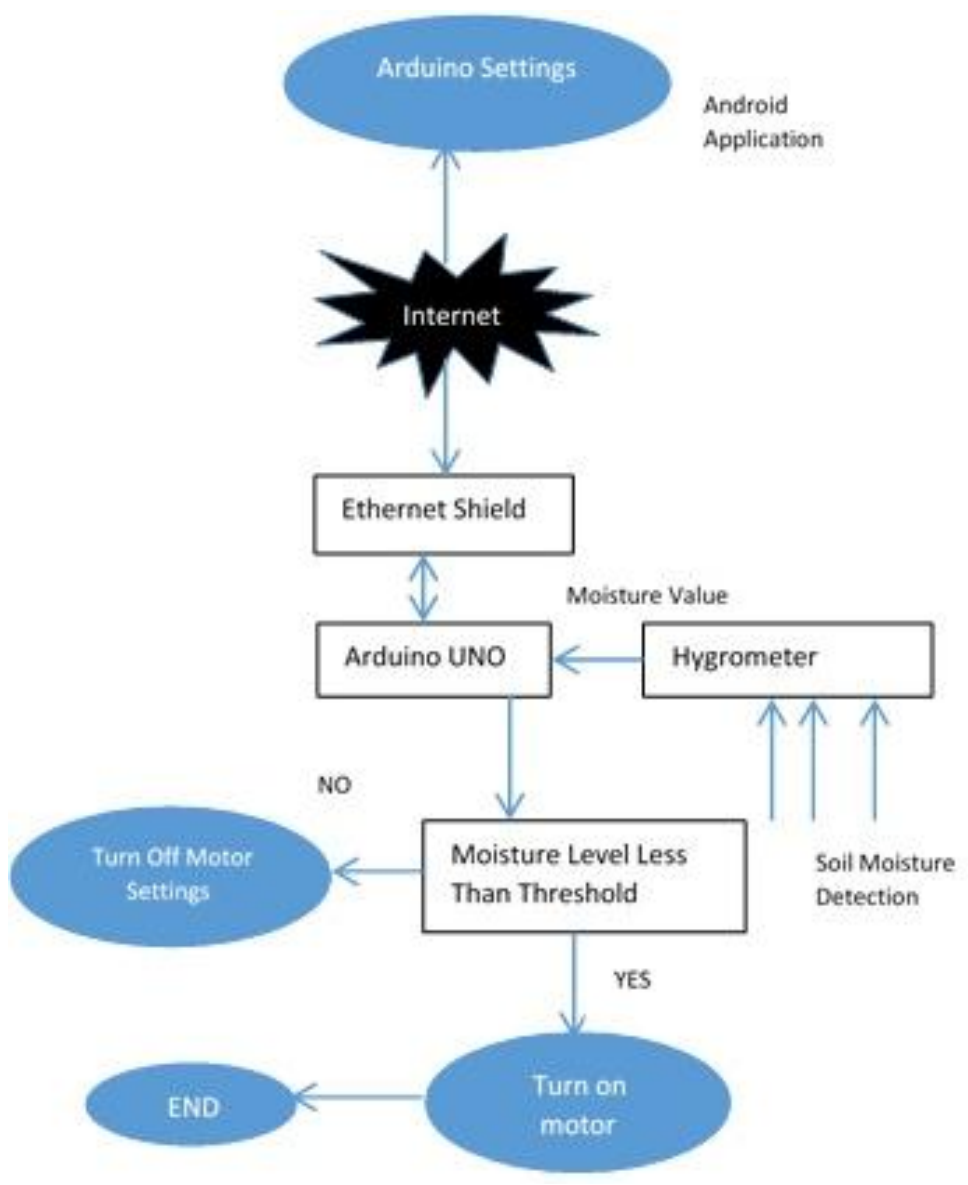

Figure 2. Flowchart for an automated watering system using feedback 
The detailed steps are as given:

- Inside the soil, a hygrometer sensor will be placed which will check the level of moisture of soil and will send the signal to Arduino UNO. Arduino will compare the level of humidity with the database value for a particular plant from the information hub and accordingly, it will do the watering for the specific plant or seed.

- If the level of moisture is less than the threshold value for that particular plant, a notification for watering a plant will be sent to the farmer through the Arduino Ethernet shield by Arduino UNO.

- Farmers will be having two options whether they want to water of plant automatically, or they will do it manually.

- Depending on the option selected by the farmer, appropriate actions will be carried out by the Arduino UNO. If a farmer decides an automatic choice, Arduino UNO will start the servo motor through the Arduino controller to make it $\mathrm{ON}$ and provide the water to the specific plant. When the moisture level reached a chosen level the working of the system will be off itself and servo motor is turned OFF. If the farmer selects the manual mode, Arduino UNO will trigger the servo motor to turn ON and the time will be decided by the farmer that when to stop the motor.

An android application's overall mechanism which will control the watering system and will assist farmers in obtaining the required information for the particular plant, is described in Figures 3 and 4. In Figure 3, several steps have been explained for farmers that how they have to sign up on an android app. Once the farmer has successfully signed up, his/her profile will be created, and he will be able to see the information's regarding agriculture through the news feed page. The newsfeed page will contain weather information and much other useful information. The working of the system after a successful login is as shown in Figure 4.

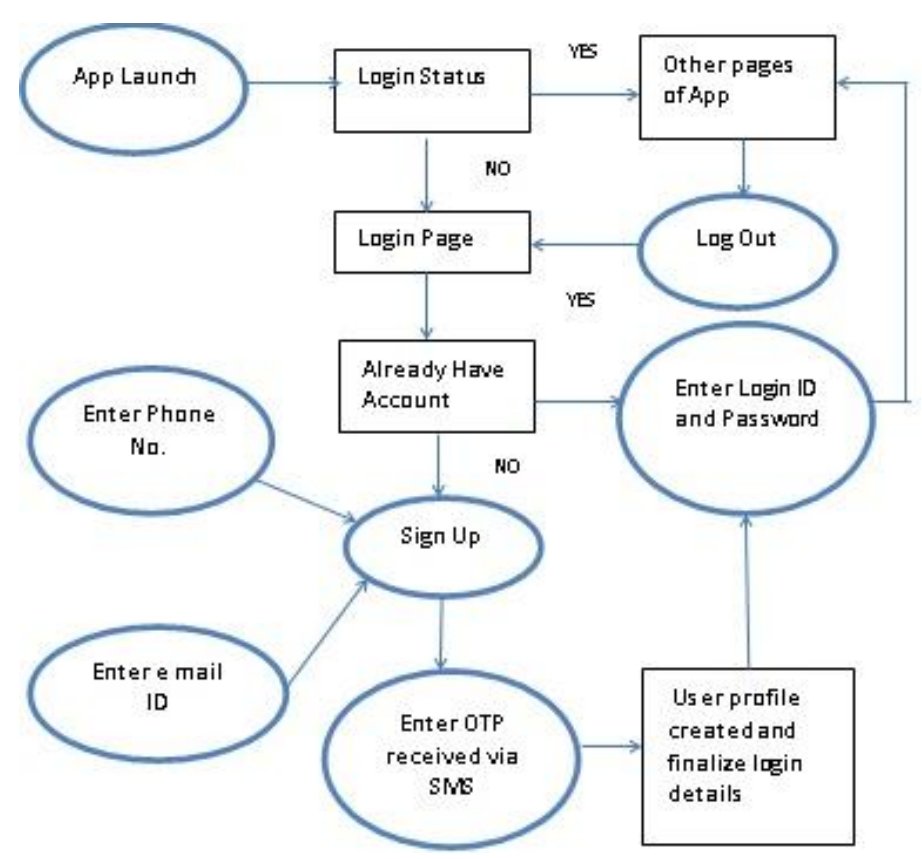

Figure 3. Steps for sign up to android application

Detailed information's regarding crops such as the cost of the seeds, the moisture level of soil required, pesticides, and fertilizers to be used, and all these will be stored in a database. An Android application will be connected to the database which can be used as a source of data using a regression algorithm along with crucial points like crop, soil type, area, seeds, and weather conditions. In addition to all these the farmers can share their views regarding the methods they have used in farming and the technologies they are using with the help of the android application therefore if one can see that this application will be beneficial to the farmers in seeking information with just a few clicks.

Using the empirical data, the Android application will also predict the weather conditions for the coming days. To give the weather conditions, it will consider the following steps; it will find the last week's temperature along with the temperature value of the same dates of the previous four years 
and calculate the average value which will be the best-predicted temperature value. It will also pressure, wind speed, humidity, clouds. These data or information will better help the harvester to design his activity while farming processes like taking suitable prevention over an anticipated rainfall, therefore, protecting his efforts.

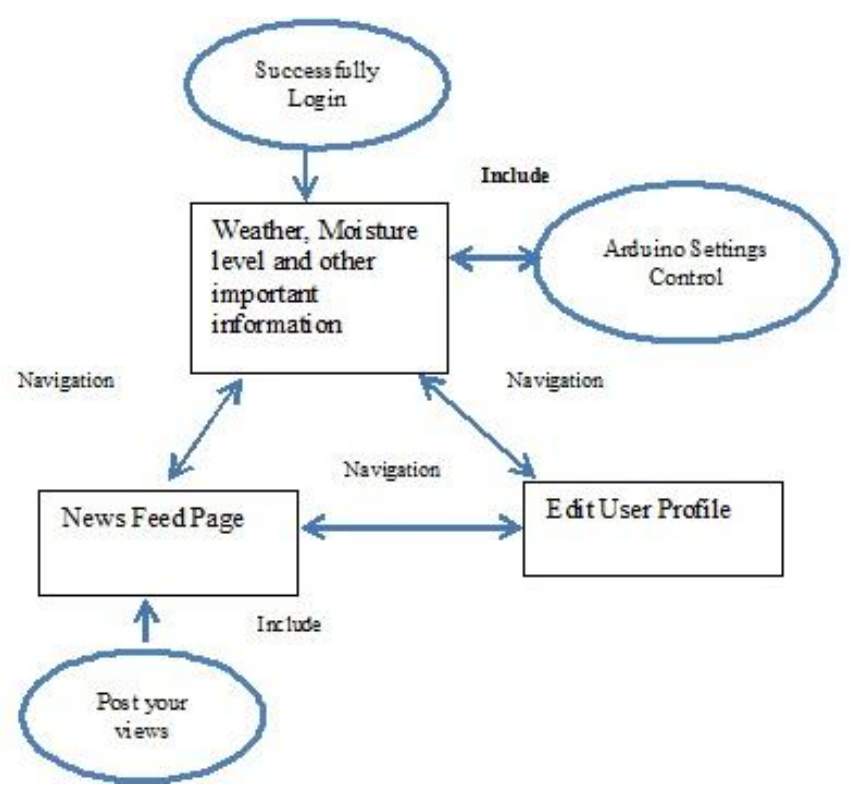

Figure 4. Working of android application

\section{CONCLUSION}

The essential part of farming is watering which is an indispensable cultural practice making this part automated will lessen the burden of farmers. In addition to this, the Android application will make the lifestyle of farmers smarter and faster. Building a water system automated will make the limited use of available water efficiently. Also, the availability of different information's regarding agriculture directly in the hand of the farmer through the use of the app without making him independent on his friend, neighbors or expecting for a message from the portal schemes of mKisan, this would make a farmer independent and can take the instant decision. Automatic system will not only make the productivity higher but will also improve the life of a farmer making it tension free as well as increasing their eagerness to explore the innovative technologies which are essential in this Digital world. The close loop system will also help to increase the GDP of the country. There is also future scope in this field by making some improvement plan which can be incorporated in this app by giving more accurate predictions about weather conditions. As different sensors are used, all the information can be recorded on the servers. Future work can also be done to build a commercial sellable product with possible additional features like harvesting, a video camera sending a live video feed to the farmer's cell phone via an IP camera.

\section{REFERENCES}

[1] A. Narechania, "An android-Arduino system to assist farmers in agricultural operations," International Journal of Mechanical And Production Engineering, vol. 3, no. 7, pp. 129-136, 2015.

[2] W. Lim, H. K. Torres, and C. M. Oppus, "An agricultural telemetry system implemented using an arduino-android interface," 7th IEEE International Conference Humanoid, Nanotechnology, Information Technology Communication, and Control, Environment, and Management (HNICEM), IEEE Philippine, pp. 12-16, 2014.

[3] A. Patil, M. Beldar, A. Naik, and S. Deshpande, "Smart farming using ardiuno and data mining," 2016 IEEE 3rd International Conference on Computing for Sustainable Global Development, New Delhi, pp 1913-1917, 2016.

[4] Economic Survey 2013-14 and CSO, Directorate of Economics and Statistics, Ministry of Agriculture, Govt. of India, "Pocket book of Agriculture Statistics-2014," Available at: http://www.eands.dacnet.nic.in/latest_2006.htm.

[5] S. Mittal, S. Gandhi, and G. Tripathi, "Working paper no. 246, socio-economic impact of mobile phones on Indian agriculture," Indian Council for Research on International Economic Relations, 2010.

[6] M. Singhal, K. Verma, and A. Shukla, "Krishi Ville-Android-based solution for Indian agriculture," 2011 IEEE 5th International Conference of Advanced Networks and Telecommunication System (ANTS), Bangalore, pp. 1-5, 2011.

[7] "Kissan Kerala," 2010, [Online], Available at: http://www.kissankerala.net/mobile/index.jsp\#mobile. 
[8] S. V. Devika, Sk. Khamuruddeen, Sk Khamurunnisa, J. Thota, and K. Shaik, "Arduino based automatic plant watering system," Int. J. of Adv. Research in Comp. Sci. and Soft. Eng. (IJARCSSE), vol. 4, no. 10, pp. 449-456, 2014.

[9] F. A. Abdullah and B. A. Samah, "Factors impinging farmers' use of agriculture technology," Asian Social Science, vol. 9, no. 3, pp. 120-124, 2013.

[10] The World Bank Data, "Employment in agriculture (\% of total employment) (Modeled ILO estimate)," Int. Labour Organization, ILOSTAT Database, 2019. Available at: http://data.worldbank.org/indicator/SL.AGR.EMPL.ZS.

[11] T. V. Prabhakar, H. S. Jamadagni, and B. S. Sadhangathan, "Datamule for agricultural applications," 2013 Texas Instruments India Educators' Conference (TIIEC), pp. 369-373, 2013.

[12] Š. Koprda, M. Magdin, and M. Munk, "Implementation of microcontroller Arduino in irrigation system," International Conference on Intelligent Computing Theories and Application, pp. 133-144, 2016.

[13] A. Hassan, S. B. Sheng, W. Md. And N. Bahaman, "An automated irrigation system using Arduino microcontroller," Internet of Things: Usage and Application, Penerbit Universiti (UTeM), pp. 3-13, 2018.

[14] S. S. Sheikh, A. Javed, M. Anas, and F. Ahmed, "Solar based smart irrigation system using PID controller," ICAET-2018, IOP Conference Series: Materials Science and Engineering, vol. 414, no. 1, pp. 1-8, 2018.

[15] M. S. Goodchild, K. D. Kuhn, M. D. Jenkins, K. J. burek, and A. J. Button, "A method for precision closed-loop irrigation using a modified PID control algorithm," Sensors \& Transducers, vol. 188, no. 5, pp. 61-68, 2015.

[16] A. Mondal, I. S. Mirsa, and S. Bose, "Building a low cost solution using wireless sensor network for agriculture application," Int. Conf. on Innovations in Electronics, Signal Processing and Comm. (IESC), pp. 61-65, 2017.

[17] L. Chhaya, P. Sharma, A. Kumar, and G. Bhagwatikar, "IoT-based implementation of field area network using smart grid communication infrastructure," Smart Cities, vol. 1, no. 1, pp. 176-189, 2018.

[18] S. N. Durga and M. Ramakrishna, "Smart irrigation system based on soil moisture using IoT," International Research Journal of Engineering and Technology (IRJET), vol. 5, no. 6, pp. 2003-2007, 2018.

[19] G. Villarrubia, J. F. de Paz, D. H. Iglesia, and J. Bajo, "Combining multi-agent systems and wireless sensor networks for monitoring crop irrigation," Sensors, vol. 17, no. 8, p. 1775, 2017.

[20] T. Senthil, S. Priyanka, S. P. Sujithaa, and K. Prabhu, "Wireless solution for smart agriculture using Intel Galileo (Gen 2)," International Journal of Innovation and Scientific Research, vol. 22, no. 2, pp. 341-347, 2016.

[21] I. Howitt and J. A. Gutierrez, "IEEE 802.15. 4 low rate-wireless personal area network coexistence issues," 2003 IEEE Wireless Communications and Networking, vol. 3, pp. 1481-1486, 2003.

[22] L. Jie, H. Ghayvat, and S. C. Mukhopadhyay, "Introducing Intel Galileo as a development platform of smart sensor: Evolution, opportunities, and challenges," IEEE 10th Conf. on Indus. Elect. and Appl. (ICIEA), pp. 1797-1802, 2015.

[23] Manoj H. G. and N. G. S. Udupa, "Application of Soil Moisture Sensor in Mixed Farming," International Research Journal of Engineering and Technology (IRJET), vol. 2, no. 4, pp. 311-314, Jul. 2015.

[24] B. B. Bhanu, K. R. Rao, J. V. N. Ramesh, and M. A. Hussain, "Agriculture field monitoring and analysis using wireless sensor networks for improving crop production," 11th Int. Conf. on Wire. and Opt. Comm. Net., pp. 1-7, 2014.

[25] V. Priya H. R. and N. Sneha, "A survey on latest IoT sensors used in agricultures on non food crops," Int. Journal of Advanced Networking \& Applications (IJANA), vol. 10, no. 5, pp. 41-46, 2019.

\section{BIOGRAPHY OF AUTHOR}

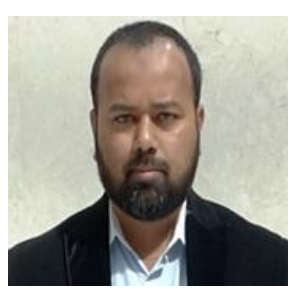

Dr. Saifur Rahman is working as an Assistant Professor at the Department of Electrical Engineering, Najran University, Najran, Saudi Arabia.. He is completed his Bachelor of Electronics \& Communication Engineering from U.P.Technical University, India in 2005. He has received his master's degree in Electronic Circuits and Systems from Integral University, India, in 2008 and awarded Ph.D. degree in Electronics \& Communication Engineering in July, from Integral University in 2015. His research areas are sensors, artificial intelligence and sensor wireless networks. 